\title{
Intracranial pressure responsiveness to positive end-expiratory pressure in different respiratory mechanics: a preliminary experimental study in pigs
}

Han Chen ${ }^{{ }^{*}}$ D, Jing Zhou ${ }^{1}$, Yi-Qin Lin ${ }^{1}$, Jian-Xin Zhou ${ }^{2}$ and Rong-Guo Yu ${ }^{1}$

\begin{abstract}
Background: Respiratory mechanics affects the effect of positive end-expiratory pressure (PEEP) on intracranial pressure (ICP). Respiratory mechanics of the lung and the chest wall was not differentiated in previous studies. In the present study, we investigated the influence of the following possible determinants of ICP responsiveness to PEEP: chest wall elastance $\left(E_{C W}\right)$, lung elastance $\left(E_{L}\right)$, and baseline ICP.

Methods: Eight healthy Bama miniature pigs were studied. The increase of $E_{L}$ was induced by instillation of hydrochloride, and the increase of $E_{c w}$ was induced by strapping the animals' chest wall and abdomen. A balloontipped catheter was placed intracranially for inducing intracranial hypertension. Six experimental conditions were investigated in sequence: 1) Normal; 2) Stiff Chest Wall; 3) Lung Injury; 4) Lung Injury + Stiff Chest Wall; 5) Lung Injury + Stiff Chest Wall + Intracranial Hypertension and 6) Lung Injury + Intracranial Hypertension. PEEP was gradually increased in a $5 \mathrm{~cm} \mathrm{H}_{2} \mathrm{O}$ interval from 5 to $25 \mathrm{~cm} \mathrm{H}_{2} \mathrm{O}$ in each condition. Blood pressure, central venous pressure, ICP, airway pressure and esophageal pressure were measured.

Results: Hydrochloride instillation significantly increased $E_{L}$ in conditions with lung injury. $E_{C w}$ significantly increased in the conditions with chest wall and abdomen strapping (all $p<0.05$ ). ICP significantly increased with increments of PEEP in all non-intracranial hypertension conditions $(p<0.001)$. The greatest cumulative increase in ICP was observed in the Stiff Chest Wall condition $(6[5.3,6.8] \mathrm{mm} \mathrm{Hg})$, while the lowest cumulative increase in ICP was observed in the Lung Injury condition $(2[1.3,3.8] \mathrm{mm} \mathrm{Hg})$. ICP significantly decreased when PEEP was increased in the intracranial hypertension conditions $(p<0.001)$. There was no significant difference in cumulative ICP change between the two intracranial hypertension conditions $(p=0.924)$.

Conclusions: Different respiratory mechanics models can be established via hydrochloride induced lung injury and chest wall and abdominal strapping. The effect of PEEP on ICP is determined by respiratory mechanics in pigs with normal ICP. However, the responsiveness of ICP to PEEP is independent of respiratory mechanics when there is intracranial hypertension.
\end{abstract}

Keywords: Intracranial pressure, Respiratory mechanics, Lung injury, Chest wall, Elastance, Esophageal pressure, Positive end-expiratory pressure

\footnotetext{
* Correspondence: baojr2@163.com

${ }^{1}$ Surgical Intensive Care Unit, Fujian Provincial Clinical College, Fujian Medical

University, No 134, Dongjie Street, Gulou District, Fuzhou 350001, Fujian,

China

Full list of author information is available at the end of the article
}

(c) The Author(s). 2018 Open Access This article is distributed under the terms of the Creative Commons Attribution 4.0 International License (http://creativecommons.org/licenses/by/4.0/), which permits unrestricted use, distribution, and reproduction in any medium, provided you give appropriate credit to the original author(s) and the source, provide a link to the Creative Commons license, and indicate if changes were made. The Creative Commons Public Domain Dedication waiver (http://creativecommons.org/publicdomain/zero/1.0/) applies to the data made available in this article, unless otherwise stated. 


\section{Background}

It has been reported that a significant portion of braininjured patients can develop pulmonary complications including acute respiratory distress syndrome (ARDS) and neurogenic pulmonary edema [1-5]. Mechanical ventilation is needed in this population, and positive end-expiratory pressure (PEEP) is used to improve oxygenation as well as to recruit and/or prevent alveolar collapse [6-8].

However, there have long been concerns that the use of PEEP in brain-injured patients could cause increase of intracranial pressure (ICP) and deteriorate neurological status, especially in those who are with signs of cerebral edema. Previous studies yielded conflicting results in the effects of PEEP on ICP, with ICP increasing [9-13], not markedly changing [14-16] or even decreasing [17] after the application of PEEP, suggesting a multifactorial mechanism. Several possible determinants for the effect of PEEP on ICP have been proposed, including baseline ICP [11], intracranial compliance [12, 13] and respiratory mechanics $[9,10]$.

Theoretically, PEEP can increase ICP via elevating intrathoracic pressure and diminishing venous return $[18,19]$, where the transmission of PEEP into the thoracic cavity depends on the respiratory mechanics. Chapin and colleges reported that increased lung elastance $\left(E_{L}\right)$ and decreased chest wall elastance $\left(E_{C W}\right)$ can minimize the effect of PEEP on pleural pressure [20]. Clinical studies have also suggested that the effect of PEEP on ICP is attenuated when respiratory system elastance $\left(E_{R S}\right)$ increases. However, $E_{L}$ and $E_{C W}$ were not differentiated in these studies $[9,10]$. For a given increased $E_{R S}$, it might be attributed to either the increase in $E_{L}$ due to pulmonary disease (e.g. ARDS), or the increase in $E_{C W}$ due to chest wall impairment (e.g. intra-abdominal hypertension or massive pleural effusion), or both. It has been shown that the $E_{C W}$ to $E_{R S}$ ratio $\left(E_{C W} / E_{R S}\right.$ ratio) varied from 0.2 to 0.8 in mechanically ventilated patients [21]. Therefore, it is important to clarify the mechanical characteristics of both the lung and the chest wall when investigating the effects of PEEP on ICP.

Although it is known that the decrease of $E_{C W} / E_{R S}$ ratio can attenuate the effect of PEEP to pleural pressure [20], it is still unknown whether it can attenuate the effect of PEEP to ICP. We hypothesized that a greater $E_{C W} / E_{R S}$ ratio would result in a greater ICP responsiveness to increased PEEP. In this preliminary study, we investigated the influence of the following possible determinants of ICP responsiveness to PEEP: the elevated $E_{C W}$, which increases $E_{C W} / E_{R S}$ ratio; the elevated $E_{L}$, which reduces $E_{C W} / E_{R S}$ ratio; and the elevated baseline ICP.

\section{Methods}

\section{Animal preparation}

Eight healthy, male Bama miniature pigs (weight 10$20 \mathrm{~kg}$, mean $13.6 \mathrm{~kg}$ ) were studied. All animals received humane care in compliance with the National Institutes of Health guidelines for the care and use of experimental animals and with the approval of the Institutional Review Board of Fujian Provincial Hospital (Approval \# KY - 2016010). Animals were purchased from Guangxi University. Animals were fasted preoperatively. Premedication consisted of intramuscular $10-20 \mathrm{mg} / \mathrm{kg}$ ketamine, followed by an intravenous bolus of $10 \mathrm{mg}$ midazolam. Continuous sedation consisted of intravenous $0.2-1.0 \mathrm{mg} / \mathrm{kg} / \mathrm{hr}$ midazolam and $0.1-0.2 \mathrm{mcg} / \mathrm{kg} / \mathrm{hr}$ fentanyl. Maintenance fluid was administrated (lactated Ringer's solution, $5 \mathrm{~mL} / \mathrm{kg} / \mathrm{hr}$ ); additional fluids and catecholamine infusions were not allowed. Animals were placed on a heating pad in supine position. Central venous catheter was placed via right internal jugular vein for fluid infusion and central venous pressure (CVP) measurements. Arterial cannula was placed via right femoral artery to measure blood pressure. Tracheotomy was performed and a 5.5-6.5 tracheotomy cuffed tube was placed. Animals were than paralyzed via intravenous infusion of $10 \mathrm{mg}$ vecuronium bromide and mechanically ventilated with a Servo-s ventilator (Maquet, Solna, Sweden). Vecuronium bromide was continuously infused $(1 \mathrm{mg} / \mathrm{kg} / \mathrm{hr}$ ) and an additional $5 \mathrm{mg}$ bolus was administrated if there was spontaneous breathing effort, which was determined by a negative deflection in the esophageal pressure $\left(\mathrm{P}_{\mathrm{ES}}\right)$ tracing.

Animals were than turned to right lateral position. A midline, transverse incision was performed along the dorsal surface of the head to expose the underlying skull. One burr hole was created approximately $10 \mathrm{~mm}$ left/ lateral of midline and $10 \mathrm{~mm}$ anterior to the coronal suture. An intraparenchymal ICP monitor catheter (Codman Microsensor, Raynham, MA, USA) was placed through this opening. The distal tip of the catheter was placed in the exposed cortex at a depth of $1 \mathrm{~cm}$. A bedside ICP monitor (Codman ICP Express, Raynham, MA, USA) was connected. Another burr hole was created approximately $10 \mathrm{~mm}$ right/lateral of midline and $10 \mathrm{~mm}$ anterior to the coronal suture. A balloon-tipped catheter ( $5 \mathrm{~mL}, 8$ Fr Foley) was placed through the hole for inducing intracranial hypertension (IH).

Animals were turned back to supine position. A SmartCath-G esophageal balloon catheter (7003300, CareFusion Co., Yorba Linda, CA, USA) was placed to measure $\mathrm{P}_{\mathrm{ES}}$. A positive pressure occlusion test was used to confirm the proper balloon position $[22,23] . \mathrm{P}_{\mathrm{ES}}$ and airway pressure $\left(\mathrm{P}_{\mathrm{AW}}\right)$ were measured by two $\mathrm{KT}$ 100D-2 pressure transducers (KleisTEK di CosimoMicelli, Italy, range: $+/-100 \mathrm{~cm} \mathrm{H}_{2} \mathrm{O}$ ). 


\section{Experimental protocol}

Six experimental conditions were investigated in sequence (Fig. 1):

1) Normal condition;

2) Stiff Chest Wall experimental condition ( $C W$ condition);

3) Lung Injury experimental condition ( $L$ condition);

4) Lung Injury + Stiff Chest Wall experimental condition $(L+C W$ condition);

5) Lung Injury + Stiff Chest Wall $+I H$ experimental condition $(L+C W+I H$ condition $)$;

6) Lung Injury $+I H$ experimental condition $(L+I H$ condition).

In each condition, PEEP was gradually increased in a $5 \mathrm{~cm} \mathrm{H}_{2} \mathrm{O}$ interval from 5 to $25 \mathrm{~cm} \mathrm{H}_{2} \mathrm{O}$. Animal was ventilated for five minutes after each PEEP increment to allow ICP stabilization. Measurements were taken after the five-minute stabilization (see below). After the last measurement of one condition (25 $\mathrm{cmH}_{2} \mathrm{O}$ of PEEP), PEEP was decreased to $5 \mathrm{cmH}_{2} \mathrm{O}$ and the preparation of the next condition was completed under a PEEP setting of $5 \mathrm{cmH}_{2} \mathrm{O}$. All ventilator settings except PEEP were not changed during the entire experiment. The pig was euthanized in the end of the experiment by overdose pentobarbital injection $(100 \mathrm{mg} / \mathrm{kg})$.
The increase of $\mathrm{E}_{\mathrm{CW}}$ was induced by strapping the animals' chest wall and abdomen with an inelastic, adjustable bellyband. In addition, two pneumatic cuffs were placed between the bellyband and the abdomen as well as the chest wall $[24,25]$. The bellyband was adjusted so that inspirations were not hampered when the pneumatic cuffs were not inflated (normal $\mathrm{E}_{\mathrm{CW}}$ ). To increase $E_{C W}$, the pneumatic cuffs were inflated to a pressure of $20 \mathrm{~cm} \mathrm{H}_{2} \mathrm{O}$ [24, 25].

The increase of $E_{L}$ was induced by slowly instillation of $0.1 \mathrm{~mol} / \mathrm{L}$ hydrochloride $(4 \mathrm{~mL} / \mathrm{kg})$ down the endotracheal tube via a thin suction catheter placed at the level of the carina. This method has been previously reported as creating an animal model with ARDS-like lung injury including lung inflammation, edema, hemorrhage, and variable lung region aeration $[25,26]$. One hour following hydrochloride administration the model was validated by achieving a pulse oxygen saturation $\leq 90 \%$.

$\mathrm{IH}$ was induced by inflating the intracranial balloon with saline at a rate of $0.5 \mathrm{~mL} / \mathrm{min}$ until the ICP was constant between 30 and $40 \mathrm{~cm} \mathrm{H}_{2} \mathrm{O}$ for > $30 \min [26,27]$.

\section{Measurements}

Mechanical ventilation was set as volume-controlled ventilation with a constant flow, an inspiratory to expiratory ratio of $1: 2$, a tidal volume $\left(\mathrm{V}_{\mathrm{T}}\right)$ of $10 \mathrm{~mL} / \mathrm{kg}$, a respiratory rate of 20 breaths/min and an inspired oxygen

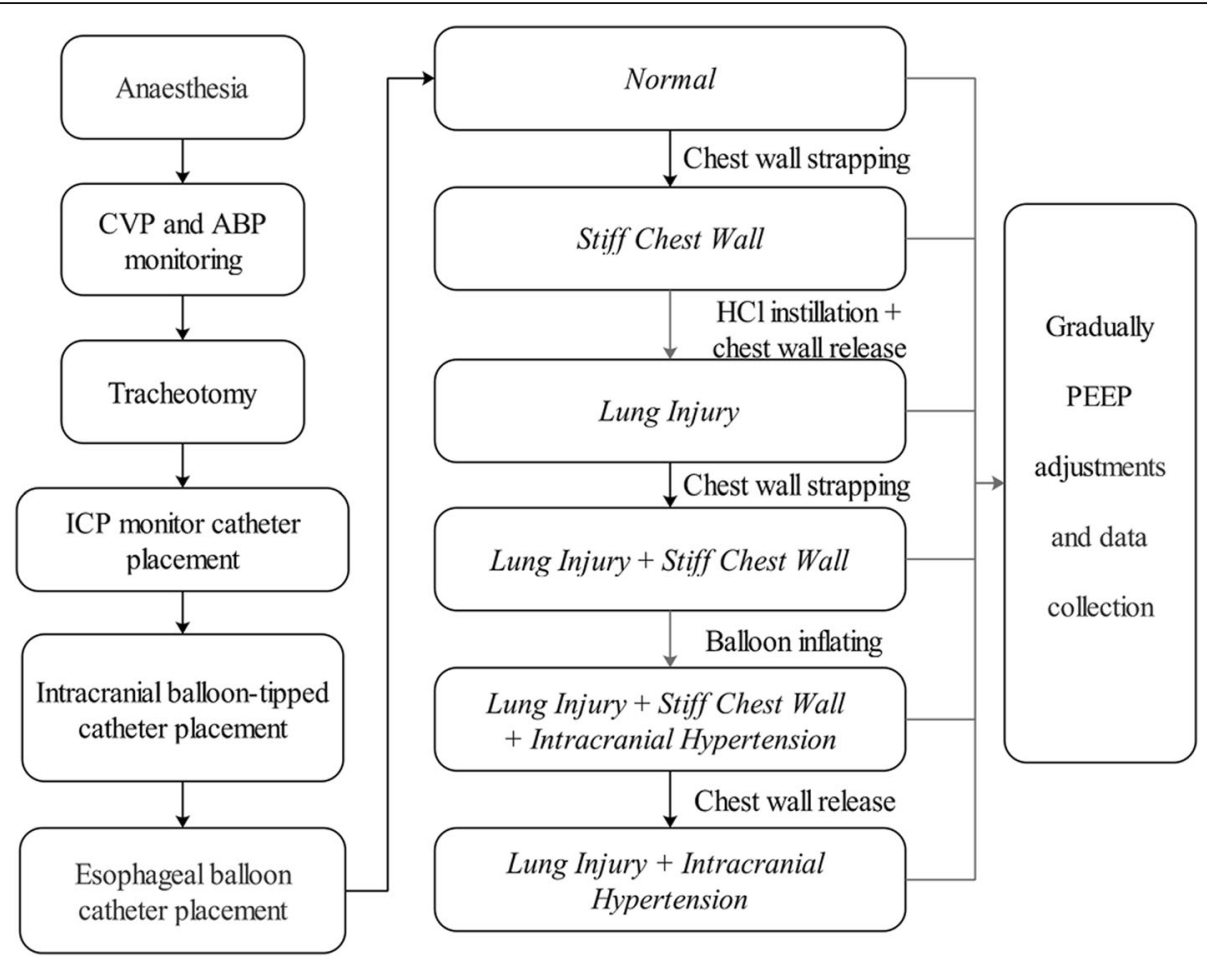

Fig. 1 Experimental flowchart 
fraction of $100 \%$. ICP, mean arterial pressure (MAP), cerebral perfusion pressure (CPP, calculated as MAP minus ICP) and CVP were measured. At each tested PEEP level, end-inspiratory and end-expiratory occlusion were performed, each for $3 \mathrm{~s}$. $\mathrm{P}_{\mathrm{ES}}$ and $\mathrm{P}_{\mathrm{AW}}$ during the last second of occlusion were recorded. Respiratory mechanics were calculated as follows:

$$
\mathrm{E}_{\mathrm{RS}}=\frac{\mathrm{P}_{\mathrm{PLAT}}-\mathrm{PEEP}_{\mathrm{TOTAL}}}{\mathrm{V}_{\mathrm{T}}}
$$

Where $P_{\text {PLAT }}$ and PEEP TOTAL $_{\text {rat }}$ represent $\mathrm{P}_{\mathrm{AW}}$ at end-inspiratory and end-expiratory occlusion, respectively.

$$
\mathrm{E}_{\mathrm{CW}}=\frac{\mathrm{P}_{\mathrm{ES}-\mathrm{EI}}-\mathrm{P}_{\mathrm{ES}-\mathrm{EE}}}{\mathrm{V}_{\mathrm{T}}}
$$

Where $\mathrm{P}_{\mathrm{ES}-\mathrm{EI}}$ and $\mathrm{P}_{\mathrm{ES}-\mathrm{EE}}$ are respective $\mathrm{P}_{\mathrm{ES}}$ determined at end-inspiratory and end-expiratory occlusion.

$$
\mathrm{E}_{\mathrm{L}}=\mathrm{E}_{\mathrm{RS}}-\mathrm{E}_{\mathrm{CW}}
$$

\section{Statistical analysis}

Continuous variables are presented as the median and inter-quartile range. Data obtained in different experimental conditions were compared by the analysis of variance for repeated measure or Scheirer-Ray-Hare test as appropriate [28]. If significant, a Student's $t$ test or Mann-Whitney $U$ test for paired data with Bonferroni correction for post-hoc multiple comparisons was applied for evaluating the differences between each experimental condition and the others. Spearman's rank-order correlation was used to explore the relationship between ICP and CVP. Significance was established at $p<0.05$. Analyses were performed with SPSS statistics software (V.23.0 IBM Corporation, New York, USA).

\section{Results}

\section{Respiratory mechanics}

There were significant differences in all respiratory mechanic parameters except for expiratory $V_{T}$ among different experimental conditions at baseline PEEP level of $5 \mathrm{~cm} \mathrm{H}_{2} \mathrm{O}$ (all $p<0.05$, Table 1). Compared to the Normal condition, hydrochloride instillation significantly increased lung driving pressure and $\mathrm{E}_{\mathrm{L}}$ in conditions with lung injury $(L, L+C W, L+C W+I H$ and $L+I H$ conditions); while $\mathrm{P}_{\mathrm{ES}-\mathrm{EE}}$, chest wall driving pressure and $E_{C W}$ significantly increased in conditions with chest wall and abdomen strapping $(C W, L+C W$ and $L+C W+I H$ conditions, Table 1).

The highest $\mathrm{E}_{\mathrm{CW}} / \mathrm{E}_{\mathrm{RS}}$ ratio was observed in the $C W$ condition which was significantly higher than the Normal condition $(p=0.033$, Table 1$)$; while the lowest $\mathrm{E}_{\mathrm{CW}} / \mathrm{E}_{\mathrm{RS}}$ ratio was observed in the $L$ condition which was significantly lower than the Normal condition $(p=$
0.035 , Table 1). There was significant difference in $\mathrm{E}_{\mathrm{CW}} /$ $\mathrm{E}_{\mathrm{RS}}$ ratio between the two conditions with $\mathrm{IH}(p=0.004$, Table 1). Figure 2 shows data of $\mathrm{E}_{\mathrm{L}}$ and $\mathrm{E}_{\mathrm{CW}}$, and the $\mathrm{E}_{\mathrm{CW}} / \mathrm{E}_{\mathrm{RS}}$ ratio.

\section{Changes of ICP in the non-IH conditions}

ICP significantly increased with increments of PEEP in all non-IH conditions $(p<0.001$, Fig. 3a). The greatest cumulative increase in ICP was observed in the $C W$ condition $(6[5.3,6.8] \mathrm{mm} \mathrm{Hg})$, which was significant higher than the other conditions ( $p$ value range: $<0.001$ to 0.018 ). The lowest cumulative increase in ICP was observed in the $L$ condition $(2[1.3,3.8] \mathrm{mm} \mathrm{Hg})$, which was significant lower than the other conditions ( $p$ $<0.001$ ). There was no significant difference in cumulative ICP change between the Normal and the $L+C W$ condition $(4[3.0,4.0]$ versus $4[2.3,4.8] \mathrm{mm} \mathrm{Hg}$, $p>0.999$, Fig. 3b).

\section{Changes of ICP in the IH conditions}

There was no difference in baseline ICP between the two IH conditions. ICP significantly decreased when PEEP was increased $(p<0.001$, Fig. 3c). There was no significant difference in cumulative ICP change between the $L+C W+I H$ and the $L+I H$ conditions $(-10[-13.5,-5.5]$ versus $-9.5[-12.5,-5.3] \mathrm{mm}$ $\mathrm{Hg}, \quad p=0.924$, Fig. 3d). There was no significant difference in ICP change between each PEEP level ( $p$ $=0.389$ ). Detailed ICP and the change of ICP at each PEEP levels was presented in Table 2.

\section{Changes of hemodynamic parameters}

Baseline CVP values were significantly higher in the conditions with chest wall strapping $(C W, L+C W$ and $L+C W+I H$ conditions) than those without chest wall strapping (Normal, $L$ and $L+I H$ conditions, $p$ value range $<0.001$ to 0.038 , Fig. 4a). CVP significantly increased as increments of PEEP in each condition, with a significant different extent of CVP increase $(p<0.001)$; the increases of CVP in the $L$ and the $L+I H$ conditions were significantly lower than those in other conditions ( $p$ value range 0.001 to 0.020 , Fig. $4 \mathrm{~b}$ ). ICP was significantly correlated to CVP in the non-IH conditions $(r=$ 0.654, $p<0.001$ ); however, ICP and CVP were no longer correlated in the IH conditions $(r=-0.066, p=0.561)$. There was no significant difference in baseline MAP among different conditions ( $p=0.125$, Fig. 4c). MAP significantly decreased when PEEP was increased in each condition, whereas the decrease of MAP in the $\mathrm{IH}$ conditions were significantly greater than those in other conditions ( $p$ value range 0.007 to 0.025 ); but no significant difference was observed between the two IH conditions ( $p=0.961$, Fig. $4 \mathrm{~d})$. CPP values in the IH conditions were significantly lower than those 


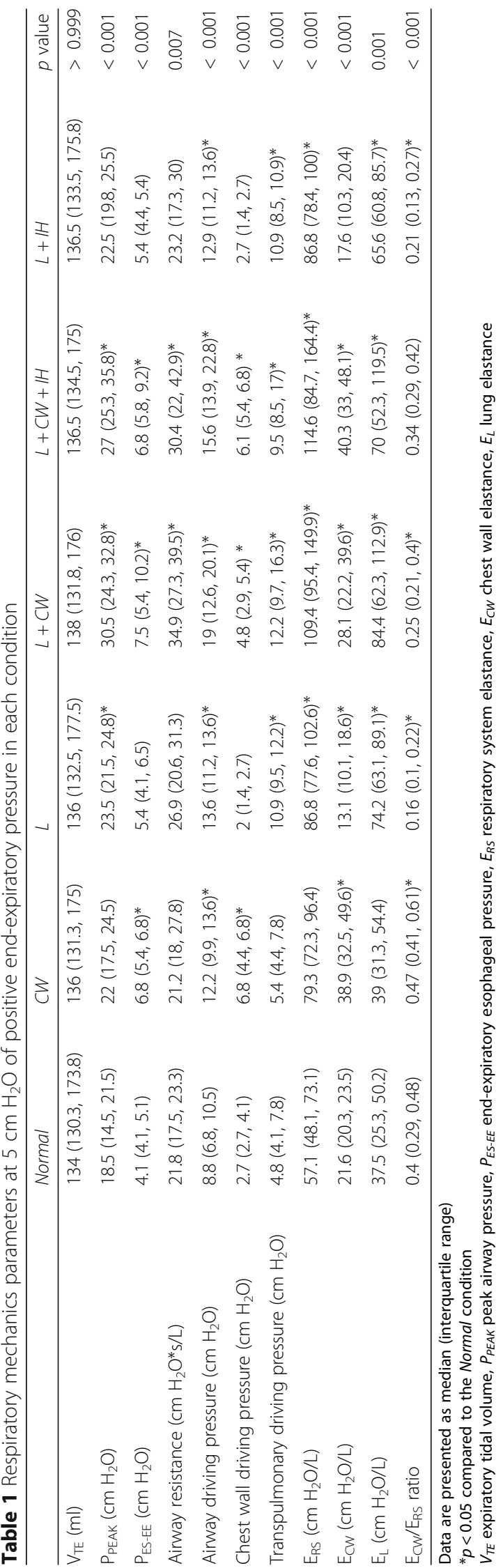




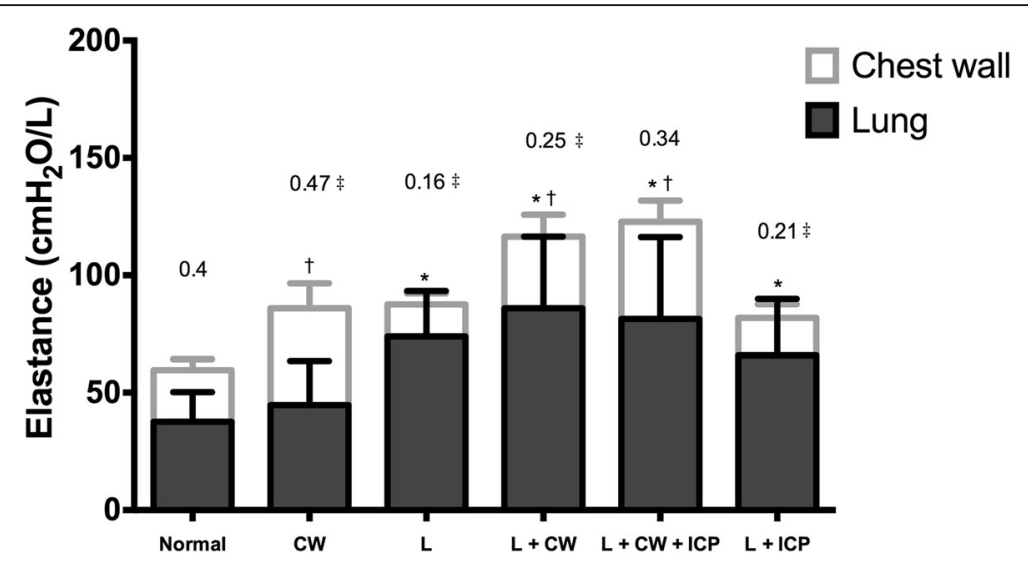

Fig. 2 Stacked histograms of chest wall elastance and lung elastance. *: compared to the Normal condition, a significant greater lung elastance $\left(E_{L}\right)$ was observed in the conditions with lung injury. t: compared to the Normal condition, a significant greater chest wall elastance ( $E_{C W}$ ) was observed in the conditions with chest and abdomen strapping. The numbers on the top of each plot are the medians of the ratio of $\mathrm{E}_{\mathrm{CW}}$ to respiratory system elastance. $\neq: p<0.05$ compared to the Normal condition

in other conditions ( $p$ value range $<0.001$ to 0.010 , Fig. 4e). There was no significant difference in the change of CPP among different conditions $(p=0.642$, Fig. 4f).

\section{Discussion}

The main findings of this preliminary study were:
1) $E_{L}$ can be increased by hydrochloride induced lung injury, accompanied with a decreased $\mathrm{E}_{\mathrm{CW}} / \mathrm{E}_{\mathrm{RS}}$ ratio. In the contrast, $\mathrm{E}_{\mathrm{CW}}$ can be increased by chest wall and abdominal strapping, accompanied by increased $E_{C W} / E_{R S}$ ratio. 2) In pigs without $\mathrm{IH}$, ICP increases as increasing of PEEP. The extent of ICP increase was determined by respiratory mechanics. The effect of PEEP on ICP was

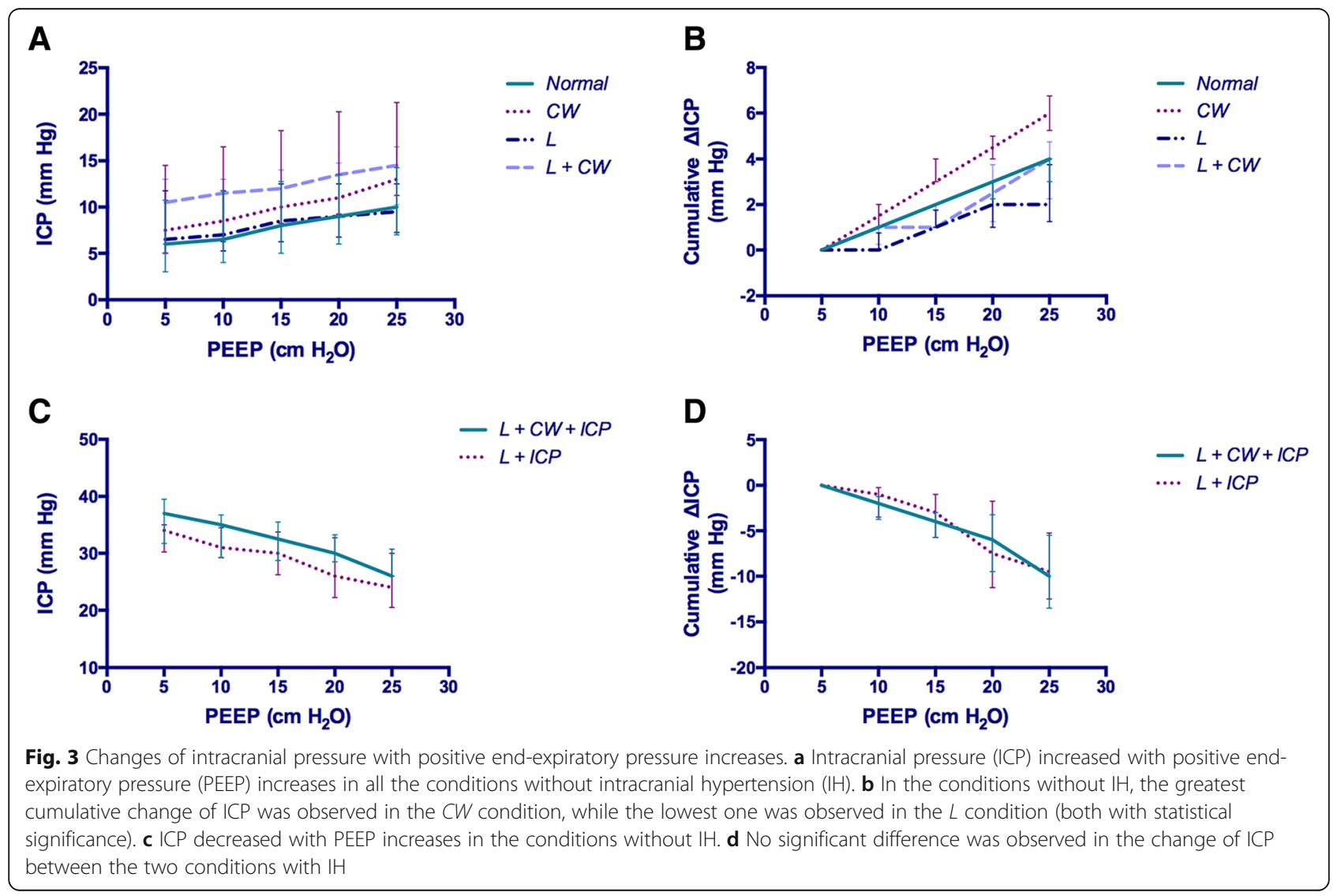


Table 2 Intracranial pressure and the change of intracranial pressure at each positive end-expiratory pressure level

\begin{tabular}{|c|c|c|c|c|}
\hline Condition & $\begin{array}{l}\text { PEEP } \\
\left(\mathrm{cm} \mathrm{H} \mathrm{H}_{2} \mathrm{O}\right)\end{array}$ & $\begin{array}{l}\text { ICP } \\
(\mathrm{mm} \mathrm{Hg})\end{array}$ & $\begin{array}{l}\triangle \mathrm{ICP} \\
(\mathrm{mm} \mathrm{Hg})\end{array}$ & $\begin{array}{l}\text { Cumulative } \triangle \mathrm{ICP} \\
(\mathrm{mm} \mathrm{Hg})\end{array}$ \\
\hline \multirow[t]{5}{*}{ Normal } & 5 & $6(3,10.8)$ & - & - \\
\hline & 10 & $6.5(4,11.8)$ & $1(1,1)$ & $1(1,1)$ \\
\hline & 15 & $8(5,12.8)$ & $1(1,1)$ & $2(2,2)$ \\
\hline & 20 & $9(6,13.5)$ & $1(1,1)$ & $3(2.3,3)$ \\
\hline & 25 & $10(7,14.3)$ & $1(0.3,1)$ & $4(3,4)$ \\
\hline \multirow[t]{5}{*}{$C W$} & 5 & $7.5(5,14.5)$ & - & - \\
\hline & 10 & $8.5(6.3,16.5)$ & $1.5(1,2)$ & $1.5(1,2)$ \\
\hline & 15 & $10(8.3,18.3)$ & $2(1,2)$ & $3(3,4)$ \\
\hline & 20 & $11(9.3,20.3)$ & $1(1,1.8)$ & $4.5(4,5)$ \\
\hline & 25 & $13(11.3,21.3)$ & $1.5(1,2)$ & $6(5.3,6.8)$ \\
\hline \multirow[t]{5}{*}{ L } & 5 & $6.5(5,11.8)$ & - & - \\
\hline & 10 & $7(5.3,11.8)$ & $0(0,0.8)$ & $0(0,0.8)$ \\
\hline & 15 & $8.5(6.3,12.5)$ & $1(1,1)$ & $1(1,1.8)$ \\
\hline & 20 & $9(6.8,12.5)$ & $0.5(0,1.8)$ & $2(1,3)$ \\
\hline & 25 & $9.5(7.3,12.5)$ & $0(0,1)$ & $2(1.3,3.8)$ \\
\hline \multirow[t]{5}{*}{$L+C W$} & 5 & $10.5(6,13)$ & - & - \\
\hline & 10 & $11.5(7,19.8)$ & $1(0.3,1)$ & $1(0.3,1)$ \\
\hline & 15 & $12(8,14)$ & $1(0,1)$ & $1(1,2)$ \\
\hline & 20 & $13.5(9.3,14.8)$ & $1(0.3,2)$ & $2.5(1.3,3.8)$ \\
\hline & 25 & $14.5(10.3,16.5)$ & $1(1,1)$ & $4(2.3,4.8)$ \\
\hline \multirow[t]{5}{*}{$L+C W+\mathbb{H}$} & 5 & $37(31.8,39.5)$ & - & - \\
\hline & 10 & $35(29.3,36.8)$ & $-2(-3.8,-1.3)$ & $-2(-3.8,-1.3)$ \\
\hline & 15 & $32.5(28.8,35.5)$ & $-2(-2,-1)$ & $-4(-5.8,-3)$ \\
\hline & 20 & $30(28.5,33.3)$ & $-1.5(-3.5,0)$ & $-6(-9.5,-3.3)$ \\
\hline & 25 & $26(26,30.8)$ & $-3.5(-4,-1.3)$ & $-10(-13.5,-5.5)$ \\
\hline \multirow[t]{5}{*}{$L+\mathbb{H}$} & 5 & $34(30.3,35)$ & - & - \\
\hline & 10 & $31(29.3,34.5)$ & $-1(-3.5,-0.3)$ & $-1(-3.5,-0.3)$ \\
\hline & 15 & $30(26.3,33.8)$ & $-2(-2.8,-0.3)$ & $-3(-5.8,-1)$ \\
\hline & 20 & $26(22.3,32.8)$ & $-2.5(-5.5,-1)$ & $-7.5(-11.3,-1.8)$ \\
\hline & 25 & $24(20.5,30)$ & $-2(-3.5,-1.3)$ & $-9.5(-12.5,-5.3)$ \\
\hline
\end{tabular}

Data are presented as median (interquartile range)

ICP intracranial pressure, PEEP positive end-expiratory pressure

enhanced in increased $\mathrm{E}_{\mathrm{CW}}$ and $\mathrm{E}_{\mathrm{CW}} / \mathrm{E}_{\mathrm{RS}}$ ratio condition, whereas the effect of PEEP on ICP was attenuated in increased $E_{L}$ and thereby reduced $E_{C W} / E_{R S}$ ratio condition. 3) In pigs with $\mathrm{IH}$, however, the increase of PEEP reduced ICP. The difference of respiratory mechanics has nothing to do with the effect of PEEP on ICP under IH conditions.

The Monro-Kellie doctrine suggests that with an intact skull, the combined volume of the brain, the blood and the cerebrospinal fluid is constant and determines the ICP [29]. An increase in volume of single component causes a decrease in volume of remaining one or both of the two components, in a certain degree, to keep ICP remained in a normal range. ICP will increase rapidly once compensation is exhausted. The PEEP-induced increase of pleural pressure may be transmitted to the intracranial cavity directly or may reduce cerebral venous drainage and eventually increase ICP $[18,30]$, where the pleural pressure serves as an intermediate link from the lung to the cranium.

The transmission of PEEP into the pleural cavity dependents on the respiratory mechanics of the lung and the chest wall. $\mathrm{P}_{\mathrm{AW}}$ equals the sum of transpulmonary pressure and pleural pressure when the airway resistance 


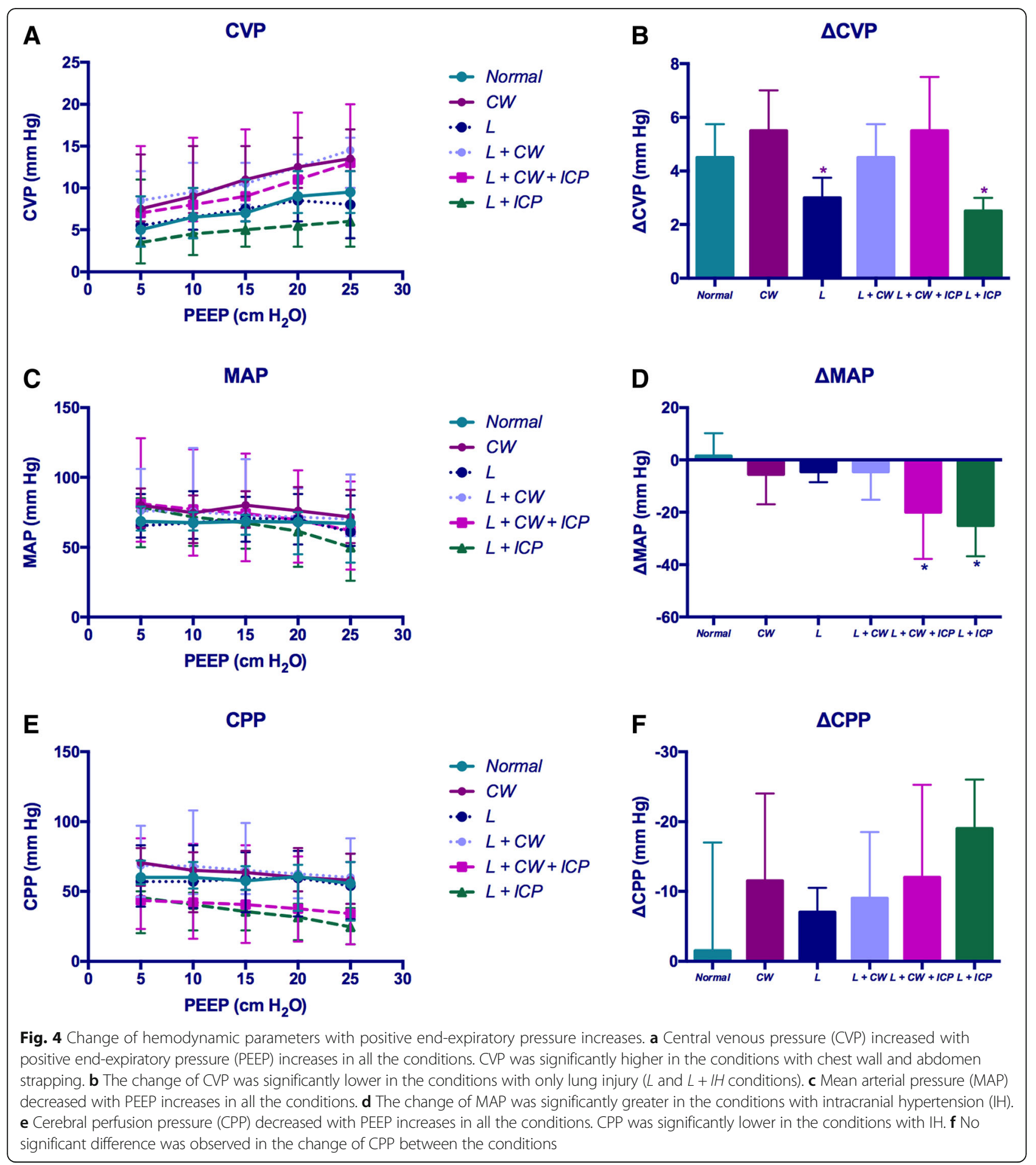

is nil (i.e. no airflow in the airway). In this situation, the distribution of $\mathrm{P}_{\mathrm{AW}}$ to pleural cavity depends on the $E_{C W} / E_{R S}$ ratio [21]. In other words, a higher $E_{C W} / E_{R S}$ ratio could lead to a greater impact of PEEP on pleural pressure, which might in turns result in a greater increase of ICP. This was supported by our data: in animals without $\mathrm{IH}$, the effect of PEEP on ICP became obvious under condition of increased $\mathrm{E}_{\mathrm{CW}} / \mathrm{E}_{\mathrm{RS}}$ ratio, but was attenuated under condition of decreased $E_{C W} / E_{R S}$ ratio (Fig. 3a and b).

Surprisingly, however, our data suggested that the increase of PEEP reduces ICP in animals with IH. This might be explained by the change of cerebral blood volume. In our study, an intracranial balloon was inflated 
to induce IH mimicking that caused by space occupying lesions. The compensatory potential of cerebrospinal fluid was exhausted and thereby the volume in the skull was predominantly determined by the intracranial blood volume in this situation since the brain is almost incompressible and has a relatively constant volume.

An increased cerebral blood volume can be caused by reduced cerebral venous drainage and/or increased arterial perfusion. The application of PEEP can reduce cerebral venous drainage as we discussed above, results in increase of cerebral venous blood volume and elevation of ICP. However, this effect might become less obvious in the IH conditions. In experimental studies conducted in dogs, it was found that the increase of ICP due to PEEP was diminished in the presence of $\mathrm{IH}$, which can be explained by the Starling resistor or waterfall concept [31, 32]. McGuire et al. found a similar phenomenon in a clinical study [11], in which ICP increased in patients with normal baseline ICP but did not significantly change in patients with elevated ICP when a maximal PEEP of $15 \mathrm{~cm} \mathrm{H}_{2} \mathrm{O}$ was applied. We speculated that the effect of PEEP on ICP from the venous side in IH pigs in the present study might be also diminished. This is supported by our data: ICP was correlated to CVP, which represents the downstream (venous returning) impedance, in the non-IH conditions; however, no such correlationshiop was observed in the $\mathrm{IH}$ conditions, which means that the change of ICP was more likely determined by the change of cerebral perfusion in the $\mathrm{IH}$ conditions.

The normal brain has several mechanisms for regulating cerebral blood flow and volume, referred as cerebral autoregulation. Under physiological conditions, vessels in the brain can regulate the vascular tone to maintain a constant cerebral blood flow in MAP between 60 and $160 \mathrm{mmHg}[33,34]$. However, recent studies suggest an asymmetric dynamic cerebral autoregulatory response that the autoregulatory ability appears to be more effective in buffering increases in MAP and CPP as compared to reductions [35-37]. In the $\mathrm{IH}$ conditions in this experiment, MAP and CPP decreased with PEEP increases. In addition, when high PEEP levels were applied, CPP dropped to a low range that was beyond the capacity of autoregulation mechanisms to maintain a constant cerebral blood flow. Therefore, it is reasonable to infer that the cerebral blood flow decreased when PEEP was increased, although we did not measure the actual cerebral blood flow in the present study. The decrease of cerebral blood flow resulted in decrease of cerebral blood volume and eventually resulted in decrease of ICP. Since there was no significant difference in MAP and CPP between the two conditions of IH (although with different respiratory mechanics), no difference was found in the change of ICP.
In the present experiment we provided sedation rather than anesthesia by midazolam and fentanyl infusion. Unlike general anesthesia (inhaled anesthetics or i.v. barbiturates), which is usually considered as a salvage therapy for refractory intracranial hypertension, sedation is more likely to be chosen in the clinical practice (in the ICUs) for intracranial hypertensive patients. Therefore, we used midazolam and fentanyl infusion (to provide sedation) instead of general anesthesia.

\section{Limitations}

Due to the nature of a preliminary study, there were many limitations in this study. First, we did not measure/control $\mathrm{PaCO}_{2}$ in this study. Therefore, the influence of $\mathrm{PaCO}_{2}$ on ICP cannot be excluded. Second, animals were not randomized to a certain condition. Instead, we tested all the conditions in sequence in each animal. Third, we used CPP as the indicator of cerebral perfusion. Although strong correlated, CPP does not always reflect cerebral perfusion. Measurement of cerebral blood flow is needed for full understanding of the effects of PEEP in intracranial hemodynamics in future studies.

\section{Conclusions}

Different respiratory mechanics models can be established via hydrochloride induced lung injury and chest wall and abdominal strapping. For pigs with normal ICP, the effect of PEEP on ICP becomes more obvious when the $E_{C W} / E_{R S}$ ratio increases, and is attenuated when the ratio decreases. For pigs with $\mathrm{IH}$, the responsiveness of ICP to PEEP is independent of respiratory mechanics and likely depends to a greater extent on the effect of PEEP on hemodynamics.

\section{Abbreviations \\ ARDS: Acute respiratory distress syndrome; CPP: Cerebral perfusion pressure; CVP: Central venous pressure; $E_{C W}$ : Chest wall elastance; $E_{L}$ : Lung elastance; $E_{R S}$ : Respiratory system elastance; ICP: Intracranial pressure; IH: Intracranial hypertension; MAP: Mean arterial pressure; $P_{\text {AW: }}$ : Airway pressure; PEEP: Positive end-expiratory pressure; $P_{E S}$ : Esophageal pressure; $P_{E S-E E}$ : End-expiratory

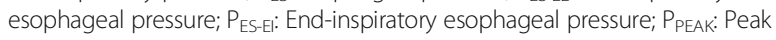 airway pressure; $\mathrm{V}_{\mathrm{TE}}$ : Expiratory tidal volume}

\section{Acknowledgements}

We thank Dr. Brian Kavanagh for his valuable suggestions for preparing the manuscript. We thank Jian-Xiang Zhao and Min Li for their technical support in the experiment.

\section{Funding}

The study was supported by National Natural Science Foundation of China (Grant No. 81701942) and Fujian Provincial Health and Family Planning Commission Youth Research Project (Grant No. 2017-2-2). The sponsors had no role in the study design, data collection, data analysis, data interpretation or writing of the manuscript.

\section{Availability of data and materials}

The datasets used and/or analyzed during the present study are available from the corresponding author on reasonable request. 


\section{Authors' contributions}

HC, JXZ and RGY participated in the design of the study and drafted the manuscript. HC, JZ, YQL participated in the experiments and data collection. All authors participated in review and revision of the manuscript. All authors read and approved the final manuscript.

\section{Ethics approval and consent to participate}

The study protocol was approved by the Institutional Review Board of Fujian Provincial Hospital.

\section{Consent for publication}

Not applicable.

\section{Competing interests}

The authors declare that they have no competing interests.

\section{Publisher's Note}

Springer Nature remains neutral with regard to jurisdictional claims in published maps and institutional affiliations.

\section{Author details}

'Surgical Intensive Care Unit, Fujian Provincial Clinical College, Fujian Medical University, No 134, Dongjie Street, Gulou District, Fuzhou 350001, Fujian, China. ${ }^{2}$ Department of Critical Care Medicine, Beijing Tiantan Hospital, Capital Medical University, Beijing, China.

\section{Received: 8 October 2017 Accepted: 28 October 2018}

\section{Published online: 05 November 2018}

\section{References}

1. Aisiku IP, Yamal JM, Doshi P, Rubin ML, Benoit JS, Hannay J, et al. The incidence of ARDS and associated mortality in severe TBI using the Berlin definition. J Trauma Acute Care Surg. 2016;80:308-12.

2. Quilez ME, Lopez-Aguilar J, Blanch L. Organ crosstalk during acute lung injury, acute respiratory distress syndrome, and mechanical ventilation. Curr Opin Crit Care. 2012:18:23-8.

3. Mascia L. Acute lung injury in patients with severe brain injury: a double hit model. Neurocrit Care. 2009:11:417-26.

4. Hoesch RE, Lin E, Young M, Gottesman RF, Altaweel L, Nyquist PA, et al. Acute lung injury in critical neurological illness. Crit Care Med. 2012:40:587-93.

5. Theodore J, Robin ED. Pathogenesis of neurogenic pulmonary oedema. Lancet. 1975;2:749-51.

6. Ranieri VM, Rubenfeld GD, Thompson BT, Ferguson ND, Caldwell E, Fan E, et al. Acute respiratory distress syndrome: the Berlin definition. JAMA. 2012; 307:2526-33.

7. Tejerina E, Pelosi P, Muriel A, Penuelas $O$, Sutherasan $Y$, Frutos-Vivar $F$, et al. Association between ventilatory settings and development of acute respiratory distress syndrome in mechanically ventilated patients due to brain injury. J Crit Care. 2016.

8. Pelosi P, Ferguson ND, Frutos-Vivar F, Anzueto A, Putensen C, Raymondos K, et al. Management and outcome of mechanically ventilated neurologic patients. Crit Care Med. 2011;39:1482-92.

9. Mascia L, Grasso S, Fiore T, Bruno F, Berardino M, Ducati A. Cerebropulmonary interactions during the application of low levels of positive endexpiratory pressure. Intensive Care Med. 2005;31:373-9.

10. Caricato A, Conti G, Della Corte F, Mancino A, Santilli F, Sandroni C, et al. Effects of PEEP on the intracranial system of patients with head injury and subarachnoid hemorrhage: the role of respiratory system compliance. J Trauma. 2005;58:571-6.

11. McGuire G, Crossley D, Richards J, Wong D. Effects of varying levels of positive end-expiratory pressure on intracranial pressure and cerebral perfusion pressure. Crit Care Med. 1997:25:1059-62

12. Burchiel K, Steege TD, Wyler AR. Intracranial pressure changes in braininjured patients requiring positive end-expiratory pressure ventilation. Neurosurgery. 1981;8:443-9.

13. Apuzzo JL, Wiess MH, Petersons V, Small RB, Kurze T, Heiden JS. Effect of positive end expiratory pressure ventilation on intracranial pressure in man. J Neurosurg. 1977:46:227-32.

14. Cooper KR, Boswell PA, Choi SC. Safe use of PEEP in patients with severe head injury. J Neurosurg. 1985;63:552-5.
15. Frost EA. Effects of positive end-expiratory pressure on intracranial pressure and compliance in brain-injured patients. J Neurosurg. 1977:47:195-200.

16. Koutsoukou A, Perraki H, Raftopoulou A, Koulouris N, Sotiropoulou C, Kotanidou $\mathrm{A}$, et al. Respiratory mechanics in brain-damaged patients. Intensive Care Med. 2006;32:1947-54.

17. Huynh T, Messer M, Sing RF, Miles W, Jacobs DG, Thomason MH. Positive end-expiratory pressure alters intracranial and cerebral perfusion pressure in severe traumatic brain injury. J Trauma. 2002;53:488-92 discussion 92-3.

18. Chang WT, Nyquist PA. Strategies for the use of mechanical ventilation in the neurologic intensive care unit. Neurosurg Clin N Am. 2013;24:407-16.

19. Nyquist $P$, Stevens RD, Mirski MA. Neurologic injury and mechanica ventilation. Neurocrit Care. 2008;9:400-8.

20. Chapin JC, Downs JB, Douglas ME, Murphy EJ, Ruiz BC. Lung expansion, airway pressure transmission, and positive end-expiratory pressure. Arch Surg. 1979:114:1193-7.

21. Gattinoni L, Chiumello D, Carlesso E, Valenza F. Bench-to-bedside review: chest wall elastance in acute lung injury/acute respiratory distress syndrome patients. Crit Care. 2004;8:350-5.

22. Chen $H$, Yang YL, Xu M, Shi ZH, He X, Sun XM, et al. Use of the injection test to indicate the oesophageal balloon position in patients without spontaneous breathing: a clinical feasibility study. J Int Med Res. 2017;45:320-31.

23. Chiumello D, Consonni D, Coppola S, Froio S, Crimella F, Colombo A. The occlusion tests and end-expiratory esophageal pressure: measurements and comparison in controlled and assisted ventilation. Ann Intensive Care. 2016:6:13.

24. Hussain SN, Pardy RL. Inspiratory muscle function with restrictive chest wall loading during exercise in normal humans. J Appl Physiol (1985). 1985:58: 2027-32.

25. Staffieri F, Stripoli T, De Monte V, Crovace A, Sacchi M, De Michele M, et al. Physiological effects of an open lung ventilatory strategy titrated on elastance-derived end-inspiratory transpulmonary pressure: study in a pig model. Crit Care Med. 2012:40:2124-31.

26. Davies SW, Leonard KL, Falls RK Jr, Mageau RP, Efird JT, Hollowell JP, et al. Lung protective ventilation (ARDSNet) versus airway pressure release ventilation: ventilatory management in a combined model of acute lung and brain injury. J Trauma Acute Care Surg. 2015;78:240-9 discussion 9-51.

27. Heuer JF, Sauter P, Barwing J, Herrmann P, Crozier TA, Bleckmann A, et al. Effects of high-frequency oscillatory ventilation on systemic and cerebral hemodynamics and tissue oxygenation: an experimental study in pigs. Neurocrit Care. 2012;17:281-92.

28. Scheirer CJ, Ray WS, Hare N. The analysis of ranked data derived from completely randomized factorial designs. Biometrics. 1976:32:429-34.

29. Wilson MH. Monro-Kellie 2.0: the dynamic vascular and venous pathophysiological components of intracranial pressure. J Cereb Blood Flow Metab. 2016:36:1338-50

30. Koutsoukou A, Katsiari M, Orfanos SE, Kotanidou A, Daganou M, Kyriakopoulou $M$, et al. Respiratory mechanics in brain injury: a review. World J Crit Care Med. 2016;5:65-73.

31. Luce JM, Huseby JS, Kirk W, Butler J. A Starling resistor regulates cerebral venous outflow in dogs. J Appl Physiol Respir Environ Exerc Physiol. 1982; 53:1496-503.

32. Huseby JS, Luce JM, Cary JM, Pavlin EG, Butler J. Effects of positive endexpiratory pressure on intracranial pressure in dogs with intracranial hypertension. J Neurosurg. 1981;55:704-5.

33. Kinoshita K. Traumatic brain injury: pathophysiology for neurocritical care. J Intensive Care. 2016:4:29.

34. McBryde FD, Malpas SC, Paton JF. Intracranial mechanisms for preserving brain blood flow in health and disease. Acta Physiol (Oxf). 2017:219:274-87.

35. Numan T, Bain AR, Hoiland RL, Smirl JD, Lewis NC, Ainslie PN. Static autoregulation in humans: a review and reanalysis. Med Eng Phys. 2014:36: 1487-95.

36. Schmidt B, Klingelhofer J, Perkes I, Czosnyka M. Cerebral autoregulatory response depends on the direction of change in perfusion pressure. $J$ Neurotrauma. 2009;26:651-6.

37. Aaslid R, Blaha M, Sviri G, Douville CM, Newell DW. Asymmetric dynamic cerebral autoregulatory response to cyclic stimuli. Stroke. 2007:38:1465-9. 